Brazilian Journal

of Chemical

ISSN 0104-6632

Printed in Brazil

Engineering

www.scielo.br/bjce

Vol. 35, No. 02, pp. 289 - 298, April - June, 2018

dx.doi.org/10.1590/0104-6632.20180352s20160275

\title{
N-ACETYLCYSTEINE MICRONIZATION BY THE SEDS TECHNIQUE USING SUPERCRITICAL $\mathrm{CO}_{2}$
}

\author{
Gean Pablo S. Aguiar ${ }^{1}$, Lorenzo M. P. C. Chaves ${ }^{1}$, Daiane L. Boschetto ${ }^{1}$, \\ Angelo L. Piato ${ }^{2}$, J. Vladimir Oliveira ${ }^{1}$ and Marcelo Lanza ${ }^{1, *}$ \\ ${ }^{1}$ Department of Chemical and Food Engineering, UFSC, Florianópolis, SC, Brazil. \\ ${ }^{2}$ Department of Pharmacology, ICBS, UFRGS, Porto Alegre, Brazil.
}

(Submitted: April 29, 2016; Revised: October 7, 2016; Accepted: November 24, 2016)

\begin{abstract}
N-Acetylcysteine (NAC) is a thiol (-SH) with a strong antioxidant activity. This compound has demonstrated positive effects on chronic kidney disease, cancer, pulmonary insufficiency and other diseases. The aim of this work was to investigate the application of the Solution Enhanced Dispersion by Supercritical Fluids (SEDS) technique in the micronization of NAC using a $2^{3}$ Central Composite Design (CCD) with 3 central points, as well as to assess the influence of active compound concentration, temperature and pressure on the particle size produced. The average size of the drug before SEDS processing was verified to be $709.82 \mu \mathrm{m}$ while the best result led to a particle size of $2.86 \mu \mathrm{m}$, which means a reduction of about 248 fold. It was also observed that a reduction in particle size led to an increase in the dissolution rate with $100 \%$ dissolution.
\end{abstract}

Keywords: $\mathrm{CO}_{2}$; Supercritical fluid; NAC; SEDS.

\section{INTRODUCTION}

The micronization process is characterized by the reduction of the average particle size for the purpose of providing changes in physical structure (Chau et al., 2007). There are numerous advantages for reducing the size of pharmaceutical compounds, amongst them an increase in the dissolution rate and increased bioavailability. The use of supercritical fluid techniques in the micronization process, compared with conventional techniques, presents many advantages, such as low solvent use, ability to work with thermosensitive compounds, low concentration of residual solvent and others (He et al., 2004).
Chemically, N-acetylcysteine (NAC) is a thiol with a potent antioxidant activity. NAC showed effects in numerous conditions (Cazzola et al., 2015; Andrade et al., 2015; Elbini Dhouib et al., 2016) and, in recent years, there are a growing number of studies that show the benefits of N-acetylcysteine (NAC) in a wide range of neuropsychiatric disorders (Berk et al., 2013, Berk et al., 2014; Deepmala et al., 2015; Rosenblat et al., 2016). However, NAC has a low bioavailability through oral administration, about $10 \%$. After an oral dose, most of the NAC is metabolized into other compounds, such as cysteine and inorganic sulphite (Kelly, 1998).

\footnotetext{
* Corresponding author: +55 (48) 37212528; Fax: +55 (48) 37219687. E-mail address: m.lanza@ufsc.br

This is an extended version of the manuscript presented at the VIII Brazilian Congress of Applied Thermodynamics - CBTermo 2015, Aracaju, Brazil.
} 
The oral absorption of drugs can be improved by increasing the dissolution rate of the drug, by increasing their surface area or by enhancing the saturation solubility. The first point can be reached by micronization; however, for most drugs this procedure is not usually sufficient because even after the micronization process there is no increase in the dissolution rate. However, when the micronized compound has an increased dissolution rate, it favors the drug to reach therapeutic plasma levels, thereby increasing the bioavailability (Durán et al., 2010).

Considering the potential therapeutic use of NAC, the goal of this work was to investigate the application of solution enhanced dispersion of supercritical fluids (SEDS) micronization to reduce the particle size, increase the specific surface contact area and enhance its solubility, consequently improving the compound bioavailability.

\section{MATERIALS AND METHODS}

\section{Materials}

$\mathrm{N}$-acetylcysteine, with a purity of $99.2 \%$, was purchased from Iberoquímica Magistral Laboratory (Jundiaí/SP). Dichloromethane (DCM 99.5\%) and acetone $(99.5 \%)$ were purchased from Vetec (SigmaAldrich) and carbon dioxide (99.9\% in liquid phase) was provided by White Martins S.A.

\section{Solution Enhanced Dispersion by Supercritical Fluids Technique (SEDS)}

A schematic diagram of the experimental apparatus is presented in Figure 1. The SEDS experimental apparatus and procedure used for the micronization of the pure compound, $\mathrm{N}$-acetylcysteine, employing supercritical $\mathrm{CO}_{2}$ as anti-solvent is described in detail by Franceschi et al. (2008).

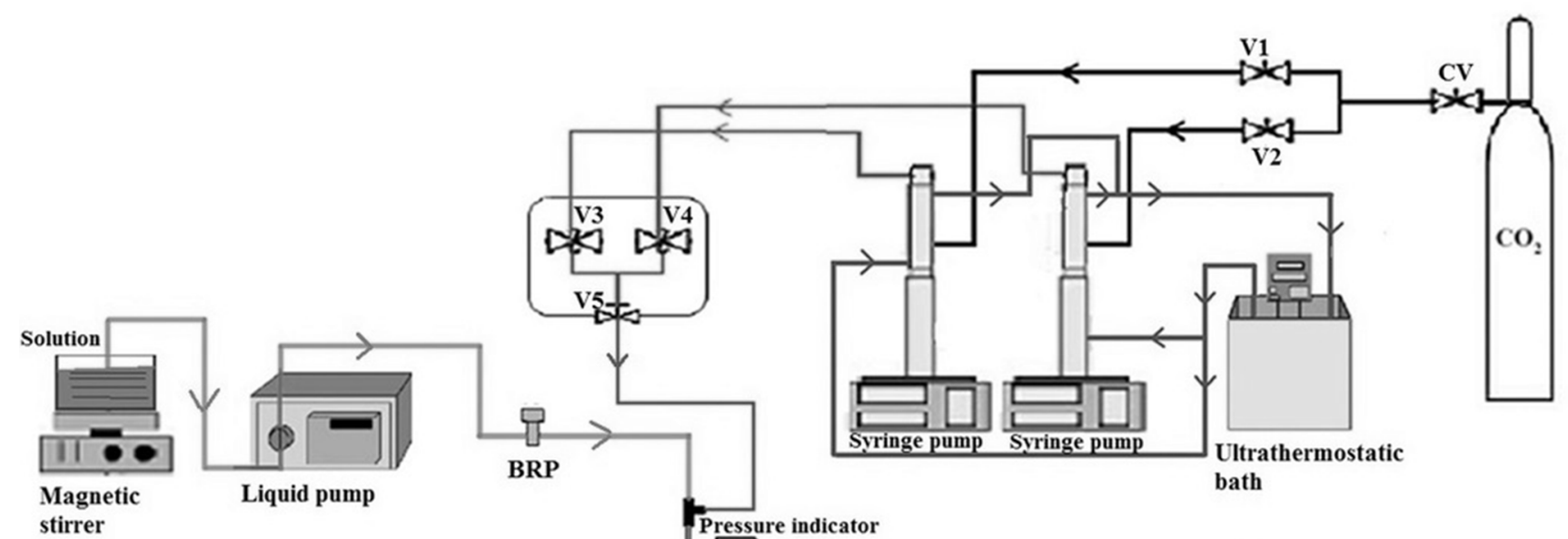

stirrer
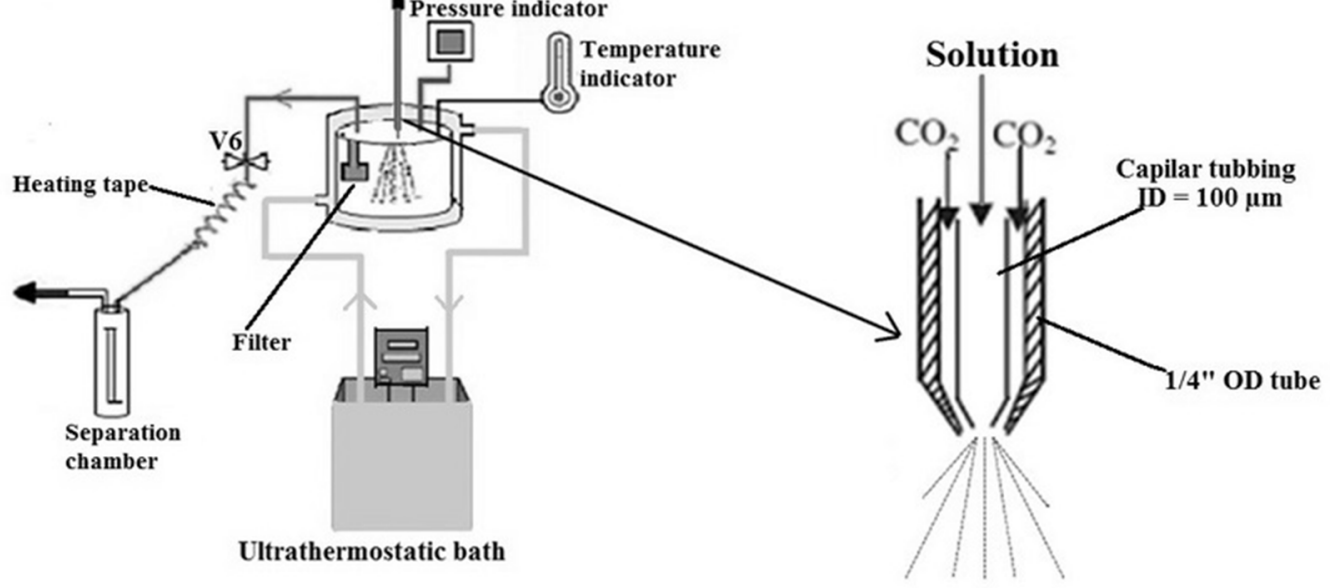

Figure 1: Schematic diagram of the experimental apparatus using the SEDS technique. CV - Check - Valve; V1, V2, V3 and V4 - Ball valve; V5 and v6 Needle valve; BRP - Back Pressure Regulator. 


\section{Experimental conditions for precipitation and} coprecipitation

For the micronization of $\mathrm{N}$-acetylcysteine the following process parameters were adopted based on previous works of the group: solute concentration of 4,12 and $20 \mathrm{mg} \cdot \mathrm{mL}^{-1}$, at 35,40 and $45^{\circ} \mathrm{C}$, solution flow rate of $1 \mathrm{~mL} \cdot \mathrm{min}^{-1}$, antisolvent flow rate of $20 \mathrm{~mL} \cdot \mathrm{min}^{-1}\left(20 \mathrm{MPa}, 5{ }^{\circ} \mathrm{C}\right.$ with resulting density of $1.0007 \mathrm{~g} \cdot \mathrm{mL}^{-1}$ ) and operating pressure of 8,10 and $12 \mathrm{MPa}$ (Franceschi et al., 2008; Priamo et al., 2010; Boschetto et al., 2013; Machado Jr et al., 2014). In this work, solute solubilization was improved by a mixture of $40 \%(\mathrm{v} / \mathrm{v})$ acetone $+60 \%(\mathrm{v} / \mathrm{v})$ dichloromethane. As mentioned, a $2^{3}$ Central Composite Design (CCD) with triplicate runs at the central point (Table 1) was employed to evaluate the influence of process variables on the morphology, size and size distribution of the particles produced.

Table 1. Variables studied in the micronization process of the samples.

\begin{tabular}{lccc}
\hline Variable & \multicolumn{3}{c}{ Level } \\
\cline { 2 - 4 } & $\mathbf{- 1}$ & $\mathbf{0}$ & $\mathbf{+ 1}$ \\
\hline Concentration $\left(\mathrm{mg} \cdot \mathrm{mL}^{-1}\right)$ & 4 & 12 & 20 \\
Pressure $(\mathrm{MPa})$ & 8 & 10 & 12 \\
Temperature $\left({ }^{\circ} \mathrm{C}\right)$ & 35 & 40 & 45 \\
\hline
\end{tabular}

\section{Morphology and determination of particle size}

The morphology of the N-acetylcysteine samples was determined using scanning electron microscopy (SEM) (JEOL JSM-6390LV, United States). The mean particle size was determined using the software Meter Size (version 1.1) (Machado Jr et al., 2014). From the calculated average particle size, the standard deviation and the variation coefficient (VC) were used as statistical tools to express the variability of the data.

\section{Fourier Transform Infrared Spectroscopy (FTIR)}

Fourier Transform Infrared Spectroscopy (FTIR) was used on the non-micronized and micronized samples in order to study possible changes of the compound after micronization. Measurements were performed in a spectrophotometer Shimadzu IRPrestige-21. Approximately $1 \mathrm{mg}$ of microparticles was triturated with $\mathrm{KBr}$ and pressed into a pellet for FTIR characterization within the spectral range of $400-4000 \mathrm{~cm}^{-1}$.

\section{Dissolution rate analysis}

To determine the dissolution rate of $\mathrm{N}$-acetylcysteine, a methodology was adapted from
Cheng et al. (2016). Samples (50 mg) were added to $100 \mathrm{~mL}$ distilled water and maintained under constant stirring $(100 \mathrm{rpm})$ at $37{ }^{\circ} \mathrm{C}$. At selected periods of 0 , $60,120,180,240,300,360$ and 420 seconds, $1.5 \mathrm{~mL}$ was collected from the solution and immediately replenished with pure solvent to maintain the original volume. Then, the samples were filtered using $0.22 \mu \mathrm{m}$ membranes and assayed for $\mathrm{N}$-acetylcysteine concentration employing the UV-visible Spectrophotometric procedure described by Raggi et al. (1982).

\section{Power X-ray diffraction (PXRD)}

PXRD data was collected from a $\theta-\theta$ D2 Phaser (Bruker) diffractometer equipped with a $\mathrm{Cu} \mathrm{K} \alpha$ source $(\lambda=1.5418 \AA)$ operated at $30 \mathrm{kV}$ and $10 \mathrm{~mA}$, using a 1-dimensional LYNXEYE Scintillation counter detector. Diffraction data was collected between 5 and $502 \theta$ degrees and $0.5 \mathrm{~s}$ counting time per step.

\section{Identification and quantification of residual solvent}

Gas chromatography was used (GC model 5975C Inert MSD brand Agilent Technologies), coupled with a mass spectrometer (GC-MS), employing a headspace vial for the identification of residual solvent in the particles produced. The operation conditions were adapted from the method described by Gudat et al. (2007) with a DB624 - $30 \mathrm{~m}$ x $0.45 \mathrm{~mm} \times 2.55 \mu \mathrm{m}$ column. The quantification of residual solvent was then investigated by gas chromatography - flame ionization detector (GC-FID) using the same operational conditions as in the GC-MS.

\section{RESULTS AND DISCUSSION}

\section{$\mathrm{N}$-acetylcysteine micronization}

Results from the $2^{3}$ Central Composite Design (CCD) are shown in Table 2, which shows the values of mean particle size $(\mathrm{X})$ as well as the variation coefficient (VC) of the experimental data.

The mean particle size for the non-micronized compound is $709.8 \mu \mathrm{m}$ and, compared with the result found in run 2, $2.9 \mu \mathrm{m}$, a relevant particle size reduction of about 248 fold is found. Franceschi et al. (2008) in studying the micronization process of $\beta$-carotene by the SEDS technique reached the smallest particle size, $3.2 \mu \mathrm{m}$, at $8 \mathrm{MPa}$. The fact that micro-scale spherical particles were obtained at the mildest process operating condition $\left(8 \mathrm{MPa}\right.$ and $35^{\circ} \mathrm{C}$ ) is very important, due to reduced product degradation and, from an industrial point of view, lower CAPEX (capital expenditure) and OPEX (operational expenditure) would be involved in the production. 
Table 2. Results of $2^{3}$ CCD experimental design of NAC micronization.

\begin{tabular}{cccccc}
\hline Run & $\begin{array}{c}\text { Concentration } \\
\left(\mathbf{m g} \cdot \mathbf{m L}^{-1}\right)\end{array}$ & $\begin{array}{c}\text { Pressure } \\
(\mathbf{M P a})\end{array}$ & $\begin{array}{c}\text { Temperature } \\
\left(\mathbf{(}^{\circ} \mathbf{C}\right)\end{array}$ & $\begin{array}{c}\mathbf{X} \\
(\boldsymbol{\mu m})\end{array}$ & VC \\
\hline $\mathbf{1}$ & 4 & 8 & 35 & 55.2 & 0.5 \\
$\mathbf{2}$ & 20 & 8 & 35 & 2.9 & 0.6 \\
$\mathbf{3}$ & 4 & 12 & 35 & 254.9 & 0.6 \\
$\mathbf{4}$ & 20 & 12 & 35 & 93.6 & 0.4 \\
$\mathbf{5}$ & 4 & 8 & 45 & 591.5 & 0.5 \\
$\mathbf{6}$ & 20 & 8 & 45 & 314.8 & 0.5 \\
$\mathbf{7}$ & 4 & 45 & 257.5 & 0.7 \\
$\mathbf{8}$ & 20 & 12 & 45 & 106.1 & 0.4 \\
$\mathbf{9}$ & 12 & 10 & 40 & 153.1 & 0.4 \\
$\mathbf{1 0}$ & 12 & 10 & 40 & 121.5 & 0.4 \\
$\mathbf{1 1}$ & 12 & 10 & 40 & 167.9 & 0.3 \\
\hline
\end{tabular}

The Pareto graph (Figure 2) reveals that the most relevant micronization process variable $(95 \%$ confidence level) is the operating temperature, which has a positive effect and therefore an increase of this parameter leads to an undesirable increase in particle size. It is interesting to note that in runs at the same pressures and concentrations, at a temperature of 45 ${ }^{\circ} \mathrm{C}$, an increase in particle size was verified (Table 2). Therefore, a temperature of $45^{\circ} \mathrm{C}$ is not interesting in this micronization process, due to the undesirable increase in particle size.

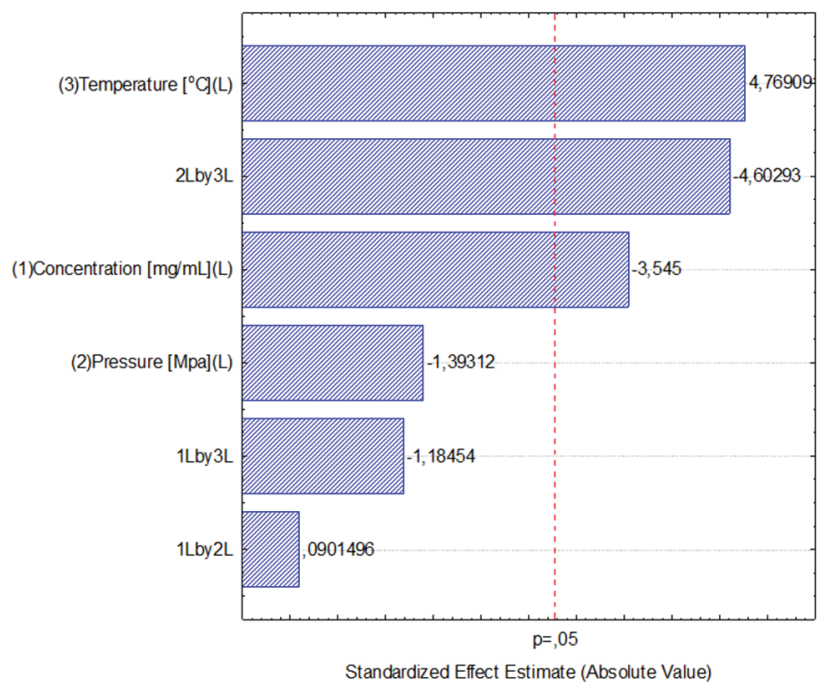

Figure 2: Pareto Chart showing the effect of micronization process parameters on the solute particle size.

Cheng et al. (2016), investigating the etoposide micronization using acetone as solvent with the SEDS technique, found that a rise in temperature led to an increase in particle size. This may be attributed to the fact that an increase in temperature at constant pressure causes a reduction in $\mathrm{CO}_{2}$ density, and hence a decrease in the solubility of etoposide in acetone, leading to a lower degree of supersaturation and an increase in the particle size. Aguiar et al. (2016) in the micronization of trans-resveratrol using the SEDS technique, also found that the increase in temperature from $35^{\circ} \mathrm{C}$ to $45^{\circ} \mathrm{C}$ resulted in larger particles, this corroborating that higher temperatures lead to the formation of larger size particles due to the improved dissolution, favored at higher temperatures, and lower level of agglomeration and consequently lesser crystal growth (Priamo et al., 2013).

According to Chen et al. (2007), the negative effect shown by the cross interaction of pressure $\mathrm{x}$ temperature on particle size might be attributed to the fact that the droplet size formed in the dispersed solution in the micronization chamber depends on the interfacial tension between the organic solution and the supercritical antisolvent, as well as their densities. Yet, an increase in pressure at constant temperature leads to an increase in $\mathrm{CO}_{2}$ density, hence a better dispersion of the solution in the antisolvent with a consequent decrease in droplet size. Mass transfer is then improved due to the increase of the diffusion coefficient of supercritical $\mathrm{CO}_{2}$, thus better removing the solvent from the solution, causing the precipitation of the compound (Chen et al., 2007; Franceschi et al., 2008).

As observed from the Pareto chart (Figure 2), the third significant process variable is the solution concentration, with an increase in concentration leading to a reduction in average particle size.

In runs 1 to 8 , in trials at the same temperature and pressure (Table 2), but with a solution concentration of $20 \mathrm{mg} \cdot \mathrm{mL}^{-1}$, a reduction in particle size was verified, making evident the influence of concentration on the 
process as in the case of runs 1 and 2 wherein the reduction was $55 \mu \mathrm{m}$ to $2.86 \mu \mathrm{m}$.

The same behavior was verified by Franceschi et al. (2008), who studied the micronization process of $\beta$-carotene by the SEDS technique and found also that the increase of solution concentration reduced the average particle size. Hong et al. (2009), using the SEDS technique for precipitation of astaxanthin, also verified that increased concentration reduces the particle diameter.

The effect of solution concentration can be explained in terms of supersaturation, because when dilute solutions are injected into the camera, the precipitation rate of supersaturation is smaller and the nucleation process is slower. Therefore, the small amount of cores generated under these conditions favors the growth of the nuclei, therefore generating larger particles, besides increasing the size distribution. When the injected solution is close to saturation, the nucleation mechanism prevails over the mechanism of particle growth due to a high supersaturation rate, consequently generating smaller-sized particles (Cardoso et al., 2008).

The fact that the concentration of the solution affects the process was also observed by Wubbolts et al. (1999), who studied ascorbic acid precipitation from an ethanol solution employing $\mathrm{CO}_{2}$ as antisolvent and found that the increase of solute concentration reduced the particle size. These authors attributed this behavior to the fact that, at high solution concentrations, at the time that the solute precipitates intense nucleation occurs, promoting the production of smaller particles with more uniform size.

As can be seen from the scanning electronic micrographs (Figure 3), all the particles obtained are of prismatic morphology. Run 2 produced more homogeneous particles in relation to other runs. In this run the smallest particle size was obtained. Franceschi et al. (2008) also obtained $\beta$-carotene particles in the form of prisms in the SEDS micronization process.
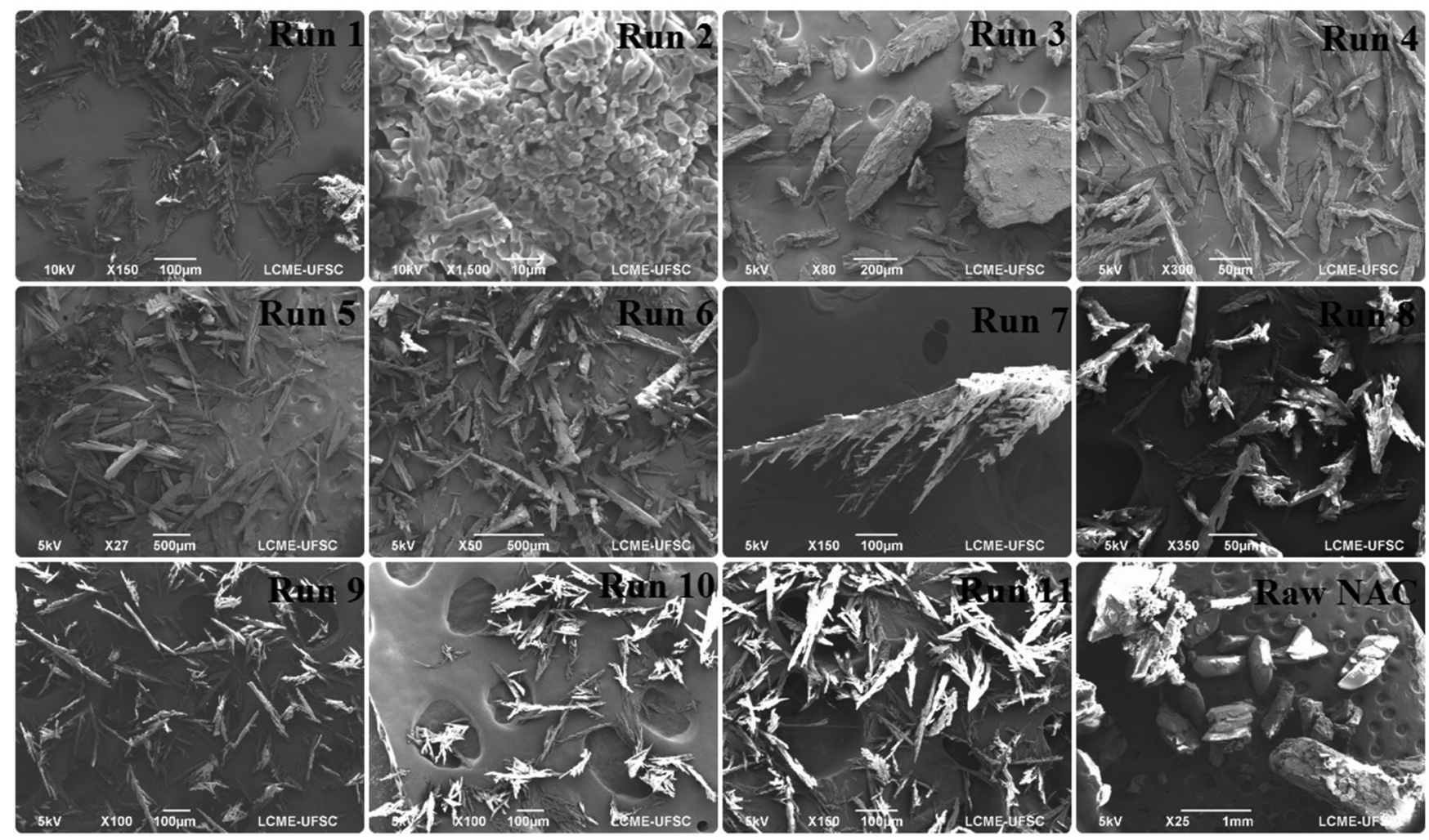

Figure 3: Scanning Electron Microscope (SEM) of the produced particles.

\section{FTIR}

It can be seen from the FTIR results shown in Figure 4 that $\mathrm{N}$-acetylcysteine was not degraded after the micronization process, nor did it suffer chemical alteration. This can be verified by the spectra which overlap. According to Silverstein (2006) it is unlikely that two different compounds present the same spectrum, thus the correlation peak to peak constitutes a good proof of identity. 


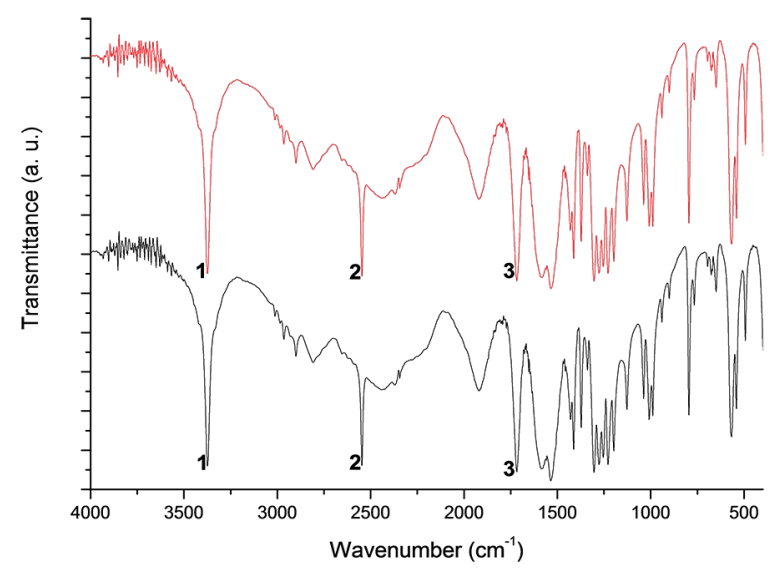

Figure 4: Infrared spectrum of micronized (red line) and non-micronized (dark line) NAC by SEDS technique. (1) NH the $3390 \mathrm{~cm}^{-1}$. (2) $\mathrm{SH}$ the $2549 \mathrm{~cm}^{-1}$. (3) $\mathrm{C}=0$ the $1720 \mathrm{~cm}^{-1}$.

FTIR results of $\mathrm{N}$-acetylcysteine samples, micronized and non-micronized, showed 3 strong absorption bands (Figure 4), typical for this compound: $3390 \mathrm{~cm}^{-1}$ (1), $2549 \mathrm{~cm}^{-1}$ (2) e $1720 \mathrm{~cm}^{-1}$ (3). The main functional groups of NAC are all well identifiable with intense bands: (1) $\mathrm{NH}$ at $3390 \mathrm{~cm}^{-1}$; (2) $\mathrm{SH}$, responsible for the odor, at $2549 \mathrm{~cm}^{-1}$ and (3) $\mathrm{C}=0$ at $1720 \mathrm{~cm}^{-1}$. The data obtained are in agreement with those reported by Boeckx et al. (2010).

\section{Dissolution rate analysis}

From Figure 5 a noticeable difference can be seen in the dissolution of micronized and raw compound, since in run 2 there was a $100 \%$ dissolution of the compound at nearly zero time. Raw $\mathrm{N}$-acetylcysteine showed a dissolution of $97.16 \%$ in $420 \mathrm{~s}$, while the product obtained in run 5 showed a dissolution of $99.76 \%$ in $300 \mathrm{~s}$. Thus, in relation to run 2 , the micronization process increased by 4 times the dissolution rate at time $0 \mathrm{~s}$ of the compound to the point that only the contact with the dissolution solution already causes total dissolution without the need of mechanical agitation.

Cheng et al. (2016), in the study of etoposide micronization with supercritical $\mathrm{CO}_{2}$ using the SEDS technique, found that the best result increased by approximately 4 times the dissolution rate. Micronized drugs provided a dissolution of $90 \%$ and raw drugs $24 \%$ at $180 \mathrm{~min}$. Hiendrawan et al. (2014), in the micronization process of fenofibrate with supercritical $\mathrm{CO}_{2}$ using the Rapid Expansion of Supercritical Solution (RESS) technique, also noted an increase in drug dissolution, obtaining $80 \%$ dissolution of the processed compound and $50 \%$ dissolution for the raw compound at the time of $90 \mathrm{~min}$.

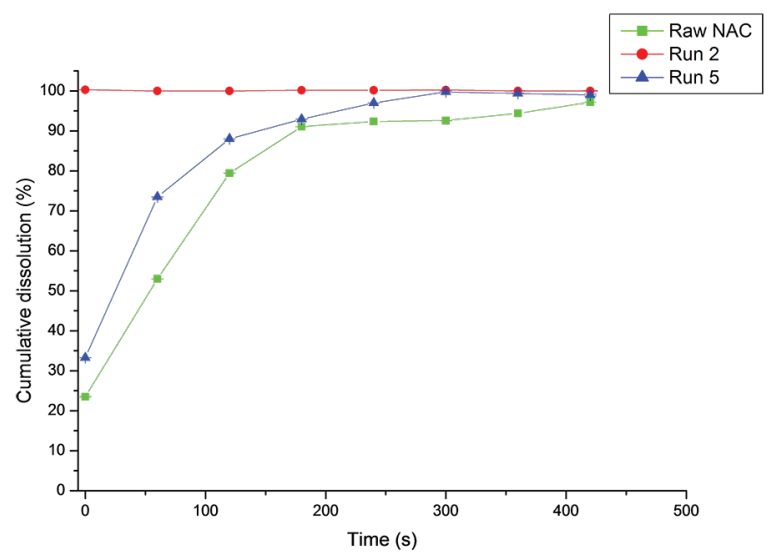

Figure 5: Dissolution profiles of NAC in distilled water.

\section{Powder X-ray diffraction (PXRD)}

Samples of micronized and non-micronized NAC were characterized by Powder X-Ray Diffraction (PXRD) to investigate the reflection diffraction of samples, with results presented in Figure 6.

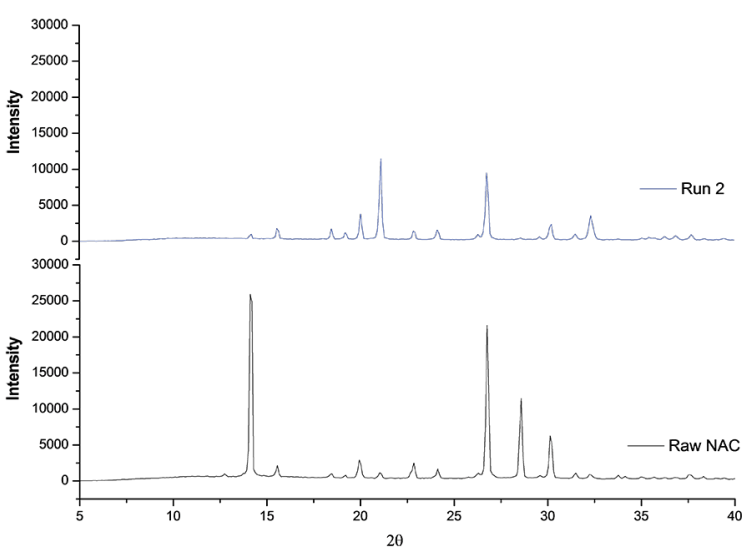

Figure 6: Powder X-Ray Diffraction (PXRD) of micronized and nonmicronized NAC particles.

The XRD patterns of the non-micronized compound presented reflections of crystallinity of $\mathrm{N}$-acetylcysteine, as observed by Desai et al. (2008), Kumar and Nangai (2013) in $2 \theta$ equal to 14.104; $15.5609 ; 18.4746 ; 19.9315 ; 21.0242 ; 22.8453$; $24.1201 ; 26.7608$ e 30.1298 . 
It can be observed from Fig. 6 that there were changes in the pattern of peaks presented by the non-micronized and micronized compound. The XRD pattern of the particles of run 2 showed a slight change in the angle of some peaks in comparison with the standard sample. The main changes were: disappearance of the peak at 12.7381; a peak shift from 14.104 to 14.195 and reduction of the intensity; a peak shift from 19.9315 to 20.0226 and increased intensity; a peak shift from 21.0242 to 21.1153 and increased intensity; a peak shift from 30.1298 to 30.2209 and reduction of the intensity.

Some peaks kept their position, but there was a reduction of the intensity: $22.8453 ; 26.7608$ and 28.5819. These differences in angles (displacements, appearance and / or disappearance of peaks) show that new polymorphic forms of the compound were generated by the SEDS process (Cheng et al., 2016). Polymorphism is the ability of a substance to exist in the solid state in two or more different crystal structures (Araujo et al., 2012). Different polymorphic forms of a same compound can present significant differences in dissolution rate, processability and physical and chemical stability (Aguiar et al., 1999). Therefore, the existence of new polymorphic forms of the compound, generated by the SEDS technique, can be related to the increased dissolution rate of a micronized compound.

\section{Residual solvent analysis}

The results of GC coupled to mass spectrometry (GC-MS) identified residual dichloromethane in samples of micronized NAC. With the aid of gas chromatography with a flame ionization detector (GCFID), $25.45 \mathrm{ppm}$ of dichloromethane were quantified in the particles of micronized NAC samples. The value of residual solvent is within the limits established by the United States Pharmacopoeia (400 ppm), European Pharmacopoeia (600 ppm), Pharmacopoeia of the People's Republic of China (600 ppm) and The National Agency for Sanitary Vigilance - ANVISA Brazil (600 ppm) (Elvassore et al., 2001) and also below the value established by the International Conference on Harmonization (ICH), document Q3C(R5) from 2011, the regulatory authority in terms of drugs and pharmaceutical industries in United States, Europe and Japan, which determines the maximum DCM concentration for human consumption, $600 \mathrm{ppm}$.

Several studies using the SEDS technique, dealing with the precipitation of solids using dichloromethane as solvent and $\mathrm{CO}_{2}$ as antisolvent, adopt drying times between 30 to $120 \mathrm{~min}$, which allows a residual amount of dichloromethane in particles in the range of 38 - 58 ppm (Hong et al., 2009; Kang et al., 2008). The present study employed 50 min of drying time, resulting in residual solvent values lower than those reported in the literature for DCM and complete removal of acetone.

The production of particles with low concentration of residual solvent is important because it ensures a safe product for the consumer (Herberger et al., 2003) and within the standards set for human consumption. Therefore, the SEDS technique enables production of microparticles presenting low concentration of DCM $(25.45 \mathrm{ppm})$ in the final product, within the limits required by regulatory agencies.

\section{CONCLUSIONS}

The particle size reduction led to increased contact surface and consequently increased solubility in aqueous solution for the active compound, which provided a $100 \%$ dissolution at $0 \mathrm{~s}$ time for run 2 (smaller particle size) and $\sim 100 \%$ dissolution for run 5 (larger particle size) at the time of $300 \mathrm{~s}$, while the raw starting material presented $97.16 \%$ dissolution at $420 \mathrm{~s}$ time. Results obtained in this study are relevant, because it was possible to reduce about 248 fold the average particle size of NAC, to $2.86 \mu \mathrm{m}$, besides providing a high dissolution rate. The best result was obtained at the lowest temperature and pressure (35 ${ }^{\circ} \mathrm{C}$ and $8 \mathrm{MPa}$, respectively), which makes the data even more relevant, especially if the benefits are considered of reducing process costs and the possibility of applying this technique to thermosensitive compounds, since FTIR accused no degradation. By XRD it can be concluded that the micronized compound has a different crystalline structure compared to the non-micronized compound that confers new properties to the compound, such as increased rate of dissolution. Finally, the micronized compound, besides presenting a fast dissolution rate, presented small residual concentrations of dichloromethane. The values obtained are well below those permitted by regulatory authorities for pharmaceutical compounds; therefore, the consumption of the micronized compound prepared by SEDS should not present risks to human health.

\section{ACKNOWLEDGMENTS}

The authors thank CNPq (Project 478520/2013-1) and CAPES for financial support and scholarships and also LCME-UFSC for the SEM analysis. 


\section{REFERENCES}

Aguiar, G.P.S., Boschetto, D.L., Chaves, L.M.P.C., Arcari, B.D., Piato, A.L., Oliveira, J.V., Lanza, M. Trans-resveratrol micronization by SEDS technique. Ind. Crops Prod. 89, 350-355 (2016).

Aguiar, M.R.M.P. de, Gemal, A.L., Gil, S., Silva, R.A. da, Characterization of polymorphism in pharmaceuticals by solid state nuclear magnetic resonance, Quím. Nova. 22, 553-564 (1999).

Andrade, K.Q., Moura, F.A., dos Santos, J.M., de Araújo, O.R.P., de Farias Santos, J.C., Goulart, M.O.F., Oxidative Stress and Inflammation in Hepatic Diseases: Therapeutic Possibilities of N-Acetylcysteine. Int. J. Mol. Sci. 16, 3026930308 (2015).

Araujo, G.L.B. de, Pitaluga JR, A., Antonio, S.G., Santos, C. de O.P., Matos, J. do R. Polimorfismo na produção de medicamentos, Rev. Ciênc. Farm. Básica E Apl. 33, 27-36 (2012).

Berk, M., Dean, O.M., Cotton, S.M., Jeavons, S., Tanious, M., Kohlmann, K., Hewitt, K., Moss, K., Allwang, C., Schapkaitz, I., Robbins, J., Cobb, H., Ng, F., Dodd, S., Bush, A.I., Malhi, G.S., The efficacy of adjunctive $\mathrm{N}$-acetylcysteine in major depressive disorder: a double-blind, randomized, placebo-controlled trial. J. Clin. Psychiatry 75, 628-636 (2014).

Berk, M., Malhi, G.S., Gray, L.J., Dean, O.M., The promise of $\mathrm{N}$-acetylcysteine in neuropsychiatry. Trends Pharmacol. Sci. 34, 167-177 (2013).

Boeckx, B., Ramaekers, R., Maes, G., A theoretical and matrix-isolation FT-IR investigation of the conformational landscape of $\mathrm{N}$-acetylcysteine. J. Mol. Spectrosc. 261, 73-81 (2010).

Boschetto, D.L., Dalmolin, I., de Cesaro, A.M., Rigo, A.A., Ferreira, S.R.S., Meireles, M.A.A., Batista, E.A.C., Oliveira, J.V., Phase behavior and process parameters effect on grape seed extract encapsulation by SEDS technique. Ind. Crops Prod. 50, 352-360 (2013).

Cardoso, M.A.T., Cabral, J.M.S., Palavra, A.M.F., Geraldes, V., CFD analysis of supercritical antisolvent (SAS) micronization of minocycline hydrochloride. J. Supercrit. Fluids 47, 247-258 (2008).

Cazzola, M., Calzetta, L., Page, C., Jardim, J., Chuchalin, A.G., Rogliani, P., Matera, M.G., Influence of $\mathrm{N}$-acetylcysteine on chronic bronchitis or COPD exacerbations: a meta-analysis. Eur. Respir. Rev. Off. J. Eur. Respir. Soc. 24, 451-461 (2015).
Chau, C.-F., Wang, Y.-T., Wen, Y.-L., Different micronization methods significantly improve the functionality of carrot insoluble fibre. Food Chem. 100, 1402-1408 (2007).

Chen, A.-Z., Pu, X.-M., Kang, Y.-Q., Liao, L., Yao, Y.-D., Yin, G.-F., Study of poly(L-lactide) microparticles based on supercritical $\mathrm{CO} 2$. J. Mater. Sci. Mater. Med. 18, 2339-2345 (2007).

Cheng, Y., Xu, W., Chen, Z., Wang, Z., Huang, D., Micronization of etoposide using solutionenhanced dispersion by supercritical $\mathrm{CO} 2$. J. Supercrit. Fluids 115, 10-16 (2016).

Deepmala, null, Slattery, J., Kumar, N., Delhey, L., Berk, M., Dean, O., Spielholz, C., Frye, R., Clinical trials of $\mathrm{N}$-acetylcysteine in psychiatry and neurology: A systematic review. Neurosci. Biobehav. Rev. 55, 294-321 (2015).

Desai, K.G.H., Mallery, S.R., Schwendeman, S.P. Formulation and Characterization of Injectable Poly(dl-lactide-co-glycolide) Implants Loaded with N-Acetylcysteine, a MMP Inhibitor. Pharm. Res. 25, 586-597 (2008).

Durán, N., Durán, M., Tasic, L., Marcato, P.D., Nanocrystal technology in pharmaceuticals. Quím. Nova 33, 151-158 (2010).

Elbini Dhouib, I., Jallouli, M., Annabi, A., Gharbi, N., Elfazaa, S., Lasram, M.M., A minireview on $\mathrm{N}$-acetylcysteine: An old drug with new approaches. Life Sci. 151, 359-363 (2016).

Elvassore, N., Bertucco, A., Caliceti, P., Production of insulin-loaded poly(ethylene glycol)/poly(l-lactide) (PEG/PLA) nanoparticles by gas antisolvent techniques. J. Pharm. Sci. 90, 1628-1636 (2001).

Franceschi, E., De Cesaro, A.M., Feiten, M., Ferreira, S.R.S., Dariva, C., Kunita, M.H., Rubira, A.F., Muniz, E.C., Corazza, M.L., Oliveira, J.V., Precipitation of $\beta$-carotene and PHBV and co-precipitation from SEDS technique using supercritical CO2. J. Supercrit. Fluids 47, 259-269 (2008).

Gudat, A.E.; Firor, R.L.; Bober, U., Better precision, sensitivity, and higher sample throughput for the analysis of residual solventes in pharmaceuticals. Agilent Application Note, Publication Number 5989-6023EN, (2007).

Herberger, J., Murphy, K., Munyakazi, L., Cordia, J., Westhaus, E., Carbon dioxide extraction of residual solvents in poly(lactide-co-glycolide) microparticles. J. Control. Release Off. J. Control. Release Soc. 90, 181-195, (2003). 
He, W.Z., Suo, Q.L., Jiang, Z.H., A, S., Hong, H.L. Precipitation of ephedrine by SEDS process using a specially designed prefilming atomizer. J. Supercrit. Fluids 31, 101-110, (2004).

Hiendrawan, S., Veriansyah, B., Tjandrawinata, R.R., Micronization of fenofibrate by rapid expansion of supercritical solution. J. Ind. Eng. Chem. 20, 54-60 (2014).

Hong, H.L., Suo, Q.L., Han, L.M., Li, C.P., Study on Precipitation of Astaxanthin in Supercritical Fluid. Powder Technol. 191, 294-298 (2009).

Kang, Y., Yin, G., Ouyang, P., Huang, Z., Yao, Y., Liao, X., Chen, A., Pu, X., Preparation of PLLA/PLGA microparticles using solution enhanced dispersion by supercritical fluids (SEDS). J. Colloid Interface Sci. 322, 87-94 (2008).

Kelly, G.S., Clinical applications of N-acetylcysteine. Altern. Med. Rev. J. Clin. Ther. 3, 114-127 (1998).

Kumar, S.S., Nangia, A. A new conformational polymorph of N-acetyl-L-cysteine. The role of S$\mathrm{H} \cdots \mathrm{O}$ and $\mathrm{C}-\mathrm{H} \cdots \mathrm{O}$ interactions. CrystEngComm 15, 6498-6505 (2013)

Machado Jr, F.R.S., Reis, D.F., Boschetto, D.L., Burkert, J.F.M., Ferreira, S.R.S., Oliveira, J.V., Burkert, C.A.V., Encapsulation of astaxanthin from Haematococcus pluvialis in PHBV by means of SEDS technique using supercritical CO2. Ind. Crops Prod. 54, 17-21 (2014).
Priamo, W.L., de Cezaro, A.M., Ferreira, S.R.S., Oliveira, J.V., Precipitation and encapsulation of $\beta$-carotene in PHBV using carbon dioxide as antisolvent. J. Supercrit. Fluids 54, 103-109 (2010).

Raggi, M.A., Cavrini, V., Di Pietra, A.M., Colorimetric determination of acetylcysteine, penicillamine, and mercaptopropionylglycine in pharmaceutical dosage forms. J. Pharm. Sci. 71, 1384-1386 (1982).

Rosenblat, J.D., Kakar, R., Berk, M., Kessing, L.V., Vinberg, M., Baune, B.T., Mansur, R.B., Brietzke, E., Goldstein, B.I., McIntyre, R.S., Antiinflammatory agents in the treatment of bipolar depression: a systematic review and meta-analysis. Bipolar Disord. 18, 89-101 (2016).

Silverstein, R.M., Identificação Espectrométrica de Compostos Orgânicos. LTC (2006).

Wubbolts, F.E., Bruinsma, O.S.L., van Rosmalen, G.M., Dry-spraying of ascorbic acid or acetaminophen solutions with supercritical carbon dioxide. J. Cryst. Growth 198-199, Part 1, 767-772 (1999). 
